\title{
De los recursos humanos a la gestión de personas: una nueva visión sobre el talento en la era digital.
}

CP 2015 , Vol.4-Nº (Monográfico II), pp. 64-66. ISSN 2014-6752. Girona (Catalunya). QUINTANA, Mónica: De los recursos humanos a la gestión de personas: una nueva visión sobre el talento en la era digital. Recibido: 10/11/2015 - Aceptado: 12/11/2015

\author{
La nueva fórmula del trabajo. Revelaciones de Google que cambiarán \\ tu forma de vivir y liderar.
}

Laszlo Bock

Penguin Random House Grupo Editorial SAU, 2015. 468 páginas

ISBN 978-84-16029-48-8

\begin{tabular}{|c|}
\hline $\begin{array}{l}\text { REVELACIONES DE GOOGLE } \\
\text { QUE CAMBIARAN } \\
\text { TUFORMA DE VVIR } \\
\text { Y LIDERAR }\end{array}$ \\
\hline $\begin{array}{l}\text { LANUEVA } \\
\text { FÓRMULA DEL } \\
\text { TRABAJO }\end{array}$ \\
\hline $\begin{array}{l}\text { LASZLO BOCK } \\
\text { VEEPRESOENE SENOR } \\
\text { EE GESTTNOD PERSONAS } \\
\text { DE GOOGLE }\end{array}$ \\
\hline
\end{tabular}

\section{Mónica QUINTANA}

CEO en Mindset.monica.quintana@mindset.tech

La nueva fórmula del trabajo es un manifiesto en el que Laszo Bock, Vicepresidente de Gestión de Personas de Google, nos invita a cambiar la manera en la que vivimos y trabajamos. A lo largo de 468 páginas el autor nos cuenta los secretos que le posibilitaron convertir a Google en una de las empresas más deseadas para trabajar por los mejores talentos del planeta.

Se trata de una obra dirigida fundamentalmente a profesionales, aunque el tono didáctico repleto de ejemplos y carente de academicismos lo convierte en una lectura apta para cualquier persona interesada en saber cómo liderar la empresa del siglo XXI, superando el viejo paradigma de los recursos humanos del ejecutivo clásico en favor de la gestión de las personas como el activo más importante.

Durante 14 capítulos, Bock expone las iniciativas sobre la materia que se implementaron en Google así como los éxitos y los aprendizajes realizados gracias a los fracasos.
El autor enfatiza la importancia de la cultura empresarial como elemento central en la gestión. En Google la misión es "organizar la información mundial y hacerla universalmente accesible y útil". Un mensaje sencillo y fácilmente comprensible que es llevado hasta las últimas consecuencias en la gestión del día a día de la empresa, que se engrana con las tres piedras angulares de la cultura googler: realización de un trabajo significativo, entendiendo que no existe un motivador más poderoso que la capacidad de influir en el mundo; transparencia, o apertura por defecto, noción según la cual la información debe ser compartida y según la que todo puede ser debatido y puesto en cuestión; expresarse en voz alta, o conferir a los empleados la posibilidad de que digan lo que piensan acerca de la empresa.

Bock sostiene que las personas actúan mejor si se les concede libertad y que una de las formas más eficientes de incrementar la productividad de los empleados es dándoles más empowerment y más capacidad para tomar decisiones. Adicionalmente, los líderes que 
son capaces de crear el entorno adecuado se transformarán en imanes para atraer a las personas con más talento del planeta, quienes gravitarán hacia los lugares donde puedan encontrar un trabajo con sentido. Ello implica que "cuando los empleados confían en los líderes se convierten en embajadores de la marca y, a su vez, fomentan un cambio progresivo en sus familias, la sociedad y el entorno".

La contratación se plantea como la actividad más importante de cualquier organización, pese a que a menudo no se le presta la atención suficiente. La mayoría de las empresas invierten más dinero en formación que en contratación, aunque no hay evidencias de que esta política implique una mejora en el rendimiento. En Google el gasto en contratación duplica al de la empresa media. La preferencia es contratar a personas inteligentes curiosas y favorecer la creación de un ecosistema de colaboración no jerárquico, buscando la motivación intrínseca para el aprendizaje continuo junto con los pares. Bock expone cómo lograron que las decisiones de contratación estuviesen más basadas en datos, para evitar las intuiciones erróneas habituales en los procesos de selección.

Otro asunto que se aborda ampliamente en el libro es el rol de los directivos, que se parece más al de un facilitador de equipo que al de un ejecutivo. A los directivos de Google se les ha quitado poder en favor del resto de los empleados y toman las decisiones importantes de forma colectiva, no pudiendo contratar ni despedir de forma unilateral. Están sometidos al mismo nivel de transparencia que el resto de los empleados y no hacen uso de símbolos de estatus que simbolicen jerarquías.

El autor propone un sistema de retribución que prima generosamente a las personas que más valor aportan a la compañía, independientemente de su puesto de trabajo.
También declara recompensar a quienes fracasaron en el desarrollo de una buena idea.

En suma, la gestión de personas en Google está relacionada con el impulso de iniciativas encaminadas a hacer felices a sus empleados mediante la búsqueda de la significación mediante el trabajo, la participación, el compartir conocimiento, la instauración de dinámicas para el aprendizaje continuo y la personalización de las condiciones de trabajo. En el nivel de gestión, estas iniciativas se instauran de la manera más sencilla posible, se testan, y se abren al escrutinio y validación por parte de los empleados.

Las normas de funcionamiento que propone el autor para la gestión de personas, son: dar sentido al trabajo, confiar, contratar a personas mejores que uno mismo, no confundir los procesos de desarrollo con la gestión del desempeño, poner el foco tanto en los mejores como en quienes tienen más dificultades, ser frugal y generoso, pagar más a quien más valor genera, implementar cambios pequeños, realizar una gestión adecuada de las expectativas y divertirse con el proceso antes de comenzarlo de nuevo.

Estos son algunos de los secretos del éxito de Google que según el autor se pueden replicar fácilmente en otras empresas, lo que quiere decir que el modelo está al alcance de todos.

En mi opinión, La nueva fórmula del trabajo es una de las obras más relevantes del año en el ámbito de la gestión empresarial y una lectura imprescindible para quienes tengan la responsabilidad de contratar o gestionar equipos.

El autor defiende en su obra una idea revolucionaria que rezuma sentido común: podemos ser más felices y productivos en nuestro trabajo. Es más: tenemos el derecho a ser felices con lo que hacemos porque es saludable dado que nos pasamos mucho 
tiempo trabajando y porque es ético realizar una contribución significativa a la sociedad.

Paradójicamente, muchas de estas medidas centradas en las personas no son llevadas a cabo por parte de las empresas pese a que la mayoría no suponen costes extra.

La reflexión inevitable es preguntarse ¿están los líderes actuales preparados para esta forma de entender la empresa? Parece evidente que en un contexto actual de transformaciones del trabajo, de aparición de tecnologías disruptivas que hacen temblar los viejos modelos de negocio y de la demanda de nuevos perfiles y nuevas competencias, algo tenga que cambiar en la gestión de las personas.
¿Este tipo de medidas son aplicables a todas las empresas? Según el autor, sí lo son. Y ésa es la razón principal para la publicación de la obra, haciendo gala de la misión de Google de organizar la información para hacerla accesible y útil.

En el epílogo del libro se plantean los retos y oportunidades para la creación de una nueva clase de recursos humanos, con profesionales híbridos y equipos multidisciplinares expertos en datos, ya que la "tecnología ha hecho más fácil intentar cosas nuevas y compartir lo que es efectivo, dándonos una oportunidad sin precedentes de cambiar el significado del trabajo". Sin duda alguna, se trata de una gran oportunidad para los nuevos profesionales de la gestión de personas y ahora también del negocio, si la sabemos aprovechar.

\section{Forma de citación}

QUINTANA, Mónica: De los recursos humanos a la gestión de personas: una nueva visión sobre el talento en la era digital. Revista Communication Papers, No8 (Monográfico II), páginas 64 a 66. Departamento de Filología y Comunicación de la Universidad de Girona. Recuperado el _ de de 2 de: http://www.communicationpapers.es 